\title{
PENGARUH PEMBERDAYAAN KELUARGA TERHADAP KUALITAS HIDUP LANSIA DI KELURAHAN KARANGSARI TANGERANG TAHUN 2017
}

\author{
Rohanah, Suyatini \\ Jurusan Keperawatan Tangerang Poltekkes Kemenkes Banten \\ Korespondensi : rohanahbadar@gmail.com
}

\begin{abstract}
The quality of life of the elderly is that the functional condition of the elderly is in a maximum or optimal condition that allows the elderly to enjoy their old age with meaning, happiness and quality, which includes physical, psychological, social and environmental health. Family empowerment in this study refers to health education for elderly families by providing material that includes knowledge and attitudes about family support. The purpose of this study was to determine the quality of life of the elderly before and after family empowerment and is there any influence of family empowerment on the quality of life of the elderly. The hypothesis of this study is that there is an influence of family empowerment on the quality of life of the elderly Design and the methodology of this study using the Quusi Experiment pre-post test. Data were analyzed using the dependent test $t$ test. Samples were taken with total sampling that met the inclusion criteria obtained by 30 respondents, namely the elderly. The study was conducted in Karangsari Village, Tangerang City in October to November 2017, the data of this study were taken using WHOQOL questionnaires. The results of statistical tests showed the pre test and post test with The value of $\mathrm{p}$ value 0.00 can be concluded that there is a significant difference in the quality of life of the elderly before and after family empowerment. In addition, there is a correlation value of 0.735 which means there is a strong influence on the process of family empowerment on the quality of life of the elderly. Suggestion: the Puskesmas / Health Services should be able to hold family empowerment activities regularly to maintain the quality of life of the elderly.
\end{abstract}

\section{Keywords: Elderly, Quality of Life, Family Empowerment.}

\begin{abstract}
ABSTRAK
Kualitas hidup lansia adalah kondisi fungsional lansia berada pada kondisi yang maksimal atau optimal sehingga memungkinkan lansia menikmati masa tuanya dengan penuh makna, bahagia dan berkualitas. yang meliputi kesehatan fisik, psikologis, sosial dan lingkungan,Pemberdayaan keluarga yang dimaksud adalah pendidikan kesehatan dengan memberikan contoh, pengetahuan dan sikap agar keoluarga dapat mendukung lansia. .Tujuan penelitian ini untuk mengetahui kualitas hidup lansia sebelum dan sesudah pemberdayaan keluarga dan adakah pengaruh pemberdayaan keluarga terhadap kualitas hidup lansia. Hipotesis penelitian ini ada pengaruh pemberdayaan keluarga terhadap kualitas hidup lansia Design dan metodologi penelitian ini menggunakan Quusi Eksperimen pre-post test. Data dianalisis menggunakan uji dependen t test. Sampel diambil dengan total sampling yang memenuhi kriteria inklusi didapat 30 responden lansia .Penelitian ini dilakukan di Kelurahan Karangsari kota Tangerang bulan Oktober sampai
\end{abstract}


Nopember 2017,Data penelitian ini diambil dengan menggunakan kuisioner baku WHOQOL.Hasil uji statistic menunjukan pre test dan post test dengan nilai $\mathrm{p}$ value 0.00 dapat disimpulkan ada perbedaan yang signifikan kualitas hidup lansia sebelum dan sesudah dilakukan pemberdayaan keluarga, selain itu didapat nilai correlation 0.735 artinya ada pengaruh yang cukup kuat proses pemberdayaan keluarga terhadap kualitas hidup lansia. Saran: kepada Puskesmas/Pelayanan Kesehatan hendaknya dapat mengadakan kegiatan pemberdayaan keluarga secara berkala untuk tetap mempertahankan kualitas hidup lansia

\section{Kata Kunci : Lansia, Kualitas Hidup, Pemberdayaan Keluarga.}

\section{PENDAHULUAN}

Menua adalah proses alami yang harus dilalui oleh semua mahluk hidup yang tidak dapat dihindari, dan merupakan hal yang wajar dialami oleh semua orang yang diberi umur panjang .Harapan semua orang hidup dimasa tua dengan bahagia ,tenang dan sejahtera.serta menikmati masa pensiun bersama anak dan cucu, kenyataannya tidak semua lanjut usia dapat menikmati segala yang diidam-idamkan. Prosesm enua tetap menimbulkan permasalahan baik secara biologis, mental maupun sosial ekonomi(Nugroho, 2000).

Dari studi pendahuluan yang dilakukan oleh penulis dapat disimpulkan banyak lansia yang tidak bisa menikmati hati tuannyan dikarenakan mereka merasa terbatas aktivitasnya, sering sakit, lingkungan kurang bersahabat, dan tidak percaya diri dengan penampilan fisiknya saat ini. hal ini menjadi bukti rendahnya kualitas hidup lanjut usia.

WHO mendefinisikan kualitas hidup sebagai persepsi individu terhadap kehidupannya di masyarakat dalam konterks budaya dan sistim nilai yang ada yang terkait dengan tujuan, harapan, standar, dan juga perhatian. Kualitas hidup dalam hal ini merupakan suatu konsep yang sangat luas yang dipengaruhi kondisi fisik individu, psikologis, tingkat kemandirian, serta hubungan individu dengan lingkungan. Kualitas hidup diartikan juga sebagai evaluasi dari kepuasan secara keseluruhan dri kehidupan seseorang. Hal ini sesuai dengan konsep sehat dari WHO yang mendefinisikan sehat sebagai keadaan sejahtera meliputi fisik,mental sosial yang tidak hanya bebas dari penyakit atau cacat fisik tetapi mampu merasa sejahtera, bahagia dalam kehidupan sehari-hari sehingga mampu mengatasi tantangan hidup sehar-hari.

Data Badan Pusat Statistik tahun 2012 menunjukan jumlah lansia di Indonesia lebih dari $9,7 \%$ secara demografi, lansia di Indonesia termasuk lima besar terbanyak di dunia. Pada tahun 2030 diperkirakan akan mencapai 36 juta,.hal ini merupakan salah satu indikator keberhasilan pencapaian pembangunan manusia secara global dan nasional. Peningkatan jumlah lansia menunjukan keberhasilan pembangunan dan tantangan pembanguan. Jumlah lanjut usia merupakan dampak dari meningkatnya usia 
harapan hidup, selain berumur panjang,lansia diharapkan memiliki kualitas hidup yang baik,sehat,produktif dan mandiri.

Sementara itu, negara melalui UU No 36 Tahun 2009 tentang Kesehatan bahwa upaya pemeliharaan kesehatan bagi lanjut usia harus ditujukan untuk menjaga agar tetap hidup sehat dan produktif secara sosial maupun ekonomi sesuai dengan martabat kemanusiaan. Pemerintah wajib menjamin ketersediaan pelayanan kesehatan dan memfasilitasi kelompok lanjut usia untuk dapat tetap hidup mandiri dan produktif, sehingga tidak menjadi beban keluarga, pemerintah serta tetap menjadi aset negara yang bermanfaat.(Kementrian Kesehatan Republik Indonesia 2013)

Perubahan yang terjadi pada lansia tidak berdiri sendiri tetapi dengan beberapa penyakit yang muncul secara bersamaan Permasalahan yang dihadapi lansia adalah perubahan fisik,psikologis,sosial dan lingkungan Masalah sosial dan lingkungan bagi lansia terutama lingkungan keluarga dipengaruhi oleh adanya orang lain baik didalam keluarga maupun diluar keluarga, begitu pula masalah lingkungan dapat didalam di linggkungan keluarga maupun lingkungan sosial.

Keluarga adalah bagian terpenting dari kehidupan lansia karena idealnya lansia menghabiskan waktunya didalam keluarga. Keluarga merupakan support system yang paling utama bagi lansia karena keluarga dapat memberikan, menyediakan dan mempersiapkan segala yang dibutuhkan lansia
Rohanah,dkk.Pengaruh Pemberdayaan Keluarga. dalam kehidupan sehari-hari. Hal -hal yang dapat dilakukan keluarga untuk lansia adalah berupa dukungan Dukungan keluarga yang dimaksud adalah dukungan emosi, dukungan instrument, dukungan informasi dan dukungan penghargaan. Agar keluarga dapat memberikan dukungan maka diperlukan pengetahuan, ketrampilan dan sikap yang baik dalam meningkatkan kualitas hidup lansia, oleh karena itu keluarga perlu diberdayakan untuk dapat membantu lansia mencapai kualitas hidup optimal

Hasil Riset yang dilakukan oleh Global Age Watch, meneliti harapan hidup lansia di 96 negara, Indonesia berada diperingkat paling bawah Index Global Age Watch diposisi ke 71, posisi ke 48 untuk domain kapabilitas, tingkat pengangguran lansia 64,8\%, domain kesehatan di posisi ke 70 , peringkat terburuk Indonesia ada di soal penghasilan hari tua, peringkat ke 86 . Berdasarkan data diatas peneliti merasa perlu melakukan pemberdayaan keluarga untuk membantu lansia mencapai tingkat kualitas yang optimal.

Penelitian yang berkaitan dengan kualitas hidup lansia telah banyak dilakukan salah satunya adalah yang dilakukan oleh DR Yulianti tahun 2015 dengan judul Hubungan Dukungan Keluarga Teradap Kualitas Hidup Lansia Di Desa Pogungrejo terhadap 38 responden dan hasilnya ada hubungan yang sangat bermakna (p: 0.05). 
Penelitian dengan judul yang sama dengan judul penulis lakukan belum ditemukan Perbedaannya dengan penelitian yang penulis lakukan adalah penulis melakukan pemberdayaan terlebih dahulu/intervensi pada keluarga dengan tujuan untuk menumbuhkan motivasi selanjutnya menjadi dukungan keluarga.

Di Lingkungan RW 13 kelurahan Karangsari banyak lansia yang masih dapat melakukan aktivitas sehari-hari walaupun kondisinya memperihatinkan. Oleh sebab itu penulis ingin melakukan suatu pemberdayaan keluarga agar dapat membantu lansia mencapai kualitas hidup yang optimal.

\section{METODELOGI}

Penelitian ini merupakan penelitian kuantitatif dengan menggunakan design penelitian kuasi - eksperimen Data dianalisis menggunakan analisis univariat dan bivariat Kegiatan penelitian ini menggunakan alat ukur berupa kuesioner untuk mengetahui kualitas hidup lansia sebelum dan sesudah dilakukan pemberdayaan keluarga dan untuk mengetahui pengaruh pemberdayaan keluarga terhadap kualitas hidup lansia di Kelurahan Karangsari Kota tangerang tahun 2017.

Analisis data dalam penelitian ini diolah dengan program statistic. Analisis univariat untuk mengetahui distribusi frekwensi karakteristik responden. Analisis bivariat menggunakan $\mathrm{Uji}$ dependen $t$ test
Rohanah,dkk.Pengaruh Pemberdayaan Keluarga. untuk mengetahui pengaruh pemberdayaan keluarga terhadap kualitas hidup lansia

\section{HASIL DAN PEMBAHASAN}

1. Analisis Univariat; Tabel 1

Distribusi Frekwensi Responden Berdasarkan Karakteristik Responden

Karakteristik Frekwensi Persentasi Umur

60-70

71-80 21

$930 \%$

Pendidikan

Rendah(SD.SMP) 27

Tinggi(SMA,PT) 3

Pekerjaan

Tidak Bekerja $\quad 24 \quad 80 \%$

Bekerja $\quad 6 \quad 20 \%$

Hubungan Keluarga

\begin{tabular}{lrr} 
Anak & 27 & $90 \%$ \\
Lain-Lain & 3 & $10 \%$ \\
\hline
\end{tabular}

Tabel 2.

\section{Perbandingan Nilai Kualitas Hidup lansia}

Sebelum dan Sesudah Dilakukan

Pemberdayaan keluarga di Kelurahan Karangsari KotaTangerang

\begin{tabular}{ccccl} 
Kel Lansia & Mean & SD & SE & P value \\
Pre Test & 79.53 & 11.658 & 2.128 & 0.00 \\
Post Test & 94.37 & 10.565 & 1.929 & \\
\hline
\end{tabular}

Tabel 2 menunjukan ada peningkatan kualitas hidup lansia setelah dilakukan pemberdayaan keluarga dengan nilai $\mathrm{p}$ value 0.00 dapat disimpulkan ada perbedaan yang signifikan antara kualitas hidup lansia sebelum dan sesudah dilakukan pemberdayaan keluarga 
TABEL 3.

Perbedaan Rerata Angka Kualitas Hidup Lansia Setelah Dilakukan Pemberdayaan Keluarga Di Kelurahan Karangsari Kota Tangerang

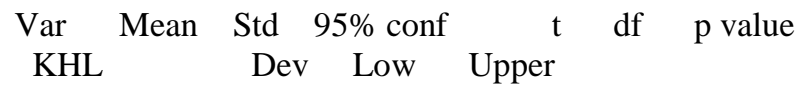

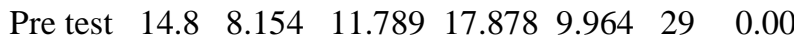

Post test

Berdasarkan tabel diatas kualitas hidup lansia hasil pre-test dan post test menunjukan nilai $\mathrm{t}=$ 9.964 dan nilai $\mathrm{p}$ value 0.00 keputusan dapat diambil ada perbedaan yang signifikan sehingga dapat disimpulkan bahwa pemberdayaan keluarga berpengaruh terhadap kualitas hidup lansia

\section{PEMBAHASAN}

Hasil penelitiuan ini menunjukan angka kualitas hidup lansia ada peningkatan sesudah dilakukan pemberdayaan keluarga . hal ini dilihat dari ratarata sebelum pemberdayaan keluarga adalah 79.53 dan sesudah pemberdayaan keluarga dengan rata-rata 94.37.ada peningkatan yang signifikan dengan nilai $\mathrm{p}$ value 0.00 dapat disimpulkan pemberdayaan keluarga mempunyai pengaruh yang signifikan terhadap kualitas hidup lansia. Hal ini sejalan dengan penelitian $\mathrm{Dr}$ Yulianti 2015 dengan judul Hubungan Dukungan Keluarga Terhadap kualitas Hidup lansia dengan nilai $\mathrm{p}$ value 0.05 artinya dukungan keluarga mempunyai hubungan yang signifikan terhadap kualitas hidup lansia.

Analisis pengaruh pemberdayaan keluarga terhadap kualitas hidup lansia dengan
Rohanah,dkk.Pengaruh Pemberdayaan Keluarga. menggunakan uji dependen $t$ test didapatkan nilai t 9.964, nilai $\mathrm{p}$ value 0.00 dapat dijelaskan bahwa pemberdayaan keluarga mempunyai pengaruh yang signifikan. Selain itu data correlation menunjukan angka 0.735 hal ini dapat dijelaskan keeratan cukup kuat. Artinya pengaruh pemberdayaan keluarga terhadap kualitas hidup lansia cukup kuat data ini juga diperkuat dengan bukti bahwa hampir semua lansia tinggal bersama anaknya,berarti dukungan keluarga benar-benar sangat berpengaruh kepada lansia. Hal ini sesuai dengan penelitian anis Ika nurrohmah 2012 tentang faktor-faktor yang mempengaruhi kualitas hidup lansia hasil penelitian menunjukan faktor psikologis yang paling dominan. Dapat dijelaskan faktor psikologis dapat diberikan melalui dukungan keluarga karena dukungan keluarga meliputi dukungan emosi, penghargaan,dukungan informasi dan dukungan instrument atau pasilitas.

\section{SIMPULAN}

Hasil penelitian ini menunjukan bahwa ada pengaruh yang signifikan pemberdayaan keluarga terhadap kualitas hidup lansia dengan nilai $\mathrm{p}$ value 0.00 dan correlation 0.735 dapat dijelaskan bahwa ada pengaruh positif yang cukup kuat pemberdayaan keluarga terhadap kualitas hidup lansia . Dengan demikian hipotesa Ha diterima.

Saran : Diharapkan pelayanan kesehatan atau pihak Puskesmas untuk menyelenggarakan pemberdayaan keluarga secara berkala karena 
terbukti pemberdayaan keluarga dapat

meningkatkan kualitas hidup lansia.

\section{DAFTAR PUSTAKA}

Anis dkk (2016) Faktor-faktor Yang Mempengaruhi Kualitas Hidup lansia FIK Muhamadiyah Malang, Jurnal keperawatan ISSN 2086-3071

Boedhi Darmojo (2011) Buku Ajar Geriatri edisi 4 Fakultas Kedokteran UI.

E.Sutikno (2011) Hubungan Fungsi Keluarga Dengan Kualitas Hidup Lansia Institut Ilmu Kesehatan Kediri Jurnal Kedokteran Indonesia VOL. 2/NO. 1/JANUARI/2011

Lilik Marifatul Azizah( 2011) Keperawatan Lanjut Usia Edisi 2 EGC

Mickey Stanley (2007) : Buku Ajar Keperawatan Gerontik Edisi 2 EGC

Sinopsis Psikiatri, Ilmu Pengetahuan Perilaku (2007). Kaplan dan Saddock Edisi VII Social psychology,(2010)Eliot Aronson,TimothyD Wilson,Robin M Akert Seventh Edition Wahyudi Nugroho (2008) Keperawatan Gerontik Edisi 3 EGC Yulianti (2015) Hubungan Dukungan Keluarga DenganKualitas Hidup lansia Di Desa Pagungrejo STIKES Aisyiyah Jogjakarta 